\section{Menarche: onset and management in London schools}

We carried out a population study in an inner city London borough with high immigration rates and wide ethnic diversity. Almost a decade after reports showed that one in eight girls attained menarche while at primary school, ${ }^{1}$ and that little more than $50 \%$ of girls' toilets had disposal facilities, ${ }^{2}$ we revisited this important public health, educational and social issue.

A questionnaire, designed with input from hospital staff and teachers, was sent to the head teachers of all 44 state primary schools in Islington, with education authority support. Information collected included: the number and ethnicities of menarcheal girls in year 5 (9-10 years) and year $6(10-11$ years), whether teaching about puberty was provided, where children accessed sanitary towels and bins, and whether cost was a factor in providing these facilities.

Fifty per cent of schools replied, providing data on 883 girls (435 in year 6; 448 in year $5)$. Overall, $17 \%$ of girls in year 6 had reached menarche, and $3 \%$ in year 5 . Figure $1 \mathrm{com}$ pares the ethnicities of the 88 girls who had attained menarche with those of the overall Islington pupil population. This clearly illustrates that black girls, but also probably Turkish girls and those of mixed ethnicities, are likely to have early pubertal maturation compared to white girls.

Girls could access sanitary towels in $91 \%$ of schools but only on asking, with none available in toilets. Most schools (95\%) provided sanitary bins but mainly only in designated toilets. Interestingly, cost did not influence sanitary facility provision in $77 \%$ of schools. Teaching about puberty was provided by $91 \%$ of schools in year 6 , and by $77 \%$ in year 5 .

Strikingly in this large cohort, menarche is achieved by one in six girls in year 6 at primary school. This study strongly suggests that early menarche is common in culturally diverse populations. Individual girls and schools therefore need to be prepared, but this is not appropriately reflected in current school provision and educational policies. Notably, we report similar statistics for sanitary facilities to those documented in UK primary schools a decade ago. ${ }^{2}$

Although most children will be taught about puberty during primary school, approximately a quarter of schools do not include such teaching in year 5 , no schools provided sanitary items without the child needing to ask, and $5 \%$ of schools had no sanitary bins available for pupils.

We acknowledge the limitations of our study, especially that information was requested from teachers. However, considering only few schools provide easily accessible sanitary facilities, teachers are likely to know which children are menstruating, and we suspect that our figures may even be an underestimate.

This study suggests the need for further national work, especially as there has been no large epidemiological study across the whole multi-cultural UK population in the last generation. Primary schools need to be aware that a significant proportion of girls will start having periods in year 6 . We suggest that a nationally agreed policy is formulated to encourage universal education,

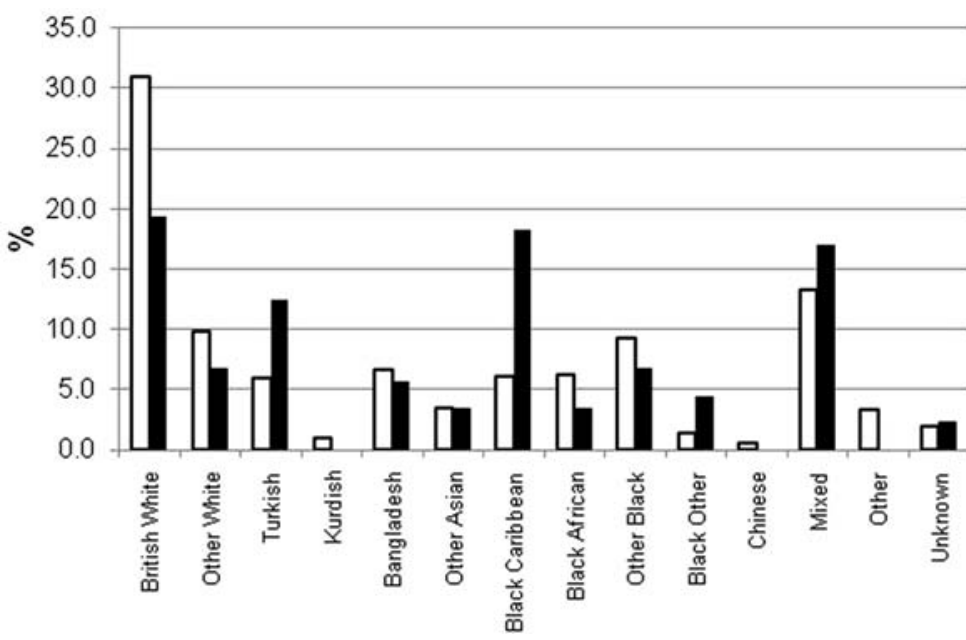

Figure 1 Ethnicities of menarcheal girls compared with 2007 pupil census data.

\section{口Ethnicities of population (Islington 2007 pupil census data, $\%)$ \\ - Ethnicities of those Who attained menarche $(\%)$ \\ Ethnicity}


and easily accessible sanitary items and disposal facilities for all girls.

Philippa Prentice, Joseph Raine

Whittington Hospital, Highgate Hill, London, UK

Correspondence to Joseph Raine, Whittington Hospital, Highgate Hill, London, UK;

joseph.raine@whittington.nhs.uk

Acknowledgements The authors would like to acknowledge $\mathrm{Dr}$ John Achermann for the idea for the study.

Competing interests None.

Ethics approval This study was conducted with the approval of Islington Local Education Authority.

Provenance and peer review Not commissioned; externally peer reviewed.

Accepted 12 August 2010

Published Online First 29 September 2010

Arch Dis Child 2011;96:111-112.

doi:10.1136/adc.2009.195404

\section{REFERENCES}

1. Whincup PH, Gilg JA, Odoki K, et al. Age of menarche in contemporary British teenagers: survey of girls born between 1982 and 1986. BMJ 2001;322:1095-6.

2. Jones R, Finlay F. Sanitary towel provision and disposal in primary schools. Child Care Health Dev 2001;27:85-92. 